\title{
La magia: encuentros entre episteme y escritura*
}

Magic: encounters between episteme and writing

\section{REsUMEN}

El presente artículo se encarga de indagar sobre la magia en tanto asunto transversal e interdisciplinar. Para el caso, es a partir de Frazer, Foucault y Derrida que se traza una hoja de ruta para pensar y zanjar las condiciones de posibilidad que dan forma al acto mágico, y que permiten pensarlo desde las prácticas "primitivas" descritas por el antropólogo escocés, pasando por la episteme del siglo XVI, hasta llegar a la escritura y su comprensión como phármakon. Esto con el objetivo de esbozar, tal vez, las continuidades y discontinuidades de la herencia de un pensamiento mágico.

Palabras clave: Magia, distancia, semejanza, imitación, escritura.

\section{ABSTRACT}

This article investigates magic as a transversal and interdisciplinary matter. For this case, it is from Frazer, Foucault and Derrida that a roadmap is drawn up to think and settle the conditions of possibility that shape the magical act and that allow it to be thought from the "primitive" practices described by the Scottish anthropologist, going through the episteme of the 16th century to finally reach writing and its understanding as phármakon.
Laura Ayala Tovar

Profesional en Estudios

Literarios y Magíster en

Educación de la Universidad

Pedagógica Nacional,

Bogotá, Colombia.

$\square$ laterrante@hotmail.com

(1) ORCID: 0000-0002-6362-7834

si Google Scholar

*El presente texto supone una selección del primer capítulo de la tesis presentada para optar por el título de Magíster en Educación de la Universidad Pedagógica Nacional. Esta llevó por título Del artificio de la palabra: notas sobre el lenguaje a través del espejo y fue presentada y sustentada en el año 2018. 
This with the aim of outlining, perhaps, the continuities and discontinuities of the inheritance of a magical thought.

Keywords: Magic, distance, similarity, imitation, writing..

“¿Quién habló de conjuros para contrarrestar la herida del propio nacimiento?"

Olga Orozco. Pavana para una infanta difunta.

- Cómo entender la magia?, ¿desde dónde asirla para hacerla legible? ¿Acaso no es nada más que el pasado remoto de las civilizaciones antiguas?, ¿es irreductible su distanciamiento con aquello que occidente se ha ocupado de clasificar como conocimiento? Si bien este texto no tiene como pretensión ofrecer una respuesta completa a las inquietudes antes planteadas, sí ofrece un acercamiento, una serie de aproximaciones que permitirían definir algunos de los rasgos que identifican el funcionamiento de la magia y de, incluso, estas letras ausentes que se vuelven a hacer presentes en su lectura.

Así las cosas, me encargaré de exponer los principales postulados del antropólogo Georges Frazer a propósito del funcionamiento de la magia simpatética, para a partir de allí establecer puentes, ante todo, con el análisis que propone Michel Foucault en torno a la episteme del siglo XVI y, finalmente, retomar La farmacia de Platón, con ánimo de esbozar la presencia y ausencia del mecanismo mágico en la comprensión de la escritura planteada por Jacques Derrida.

\section{¿Abracadabra o imitación y distancia?}

Teniendo ello como horizonte, es posible adentrarse en los postulados de los autores para con ello evidenciar las distancias y acercamientos que los entrelazan. En el caso de James George Frazer, antropólogo escocés que se ocupó de estudiar la magia, la religión y los mitos, es posible identificar una mirada eurocentrada, propia de la antropología de la época, en la que la magia se entiende como "(...) un sistema espurio de leyes naturales así como una guía errónea de conducta; es una ciencia falsa y un arte abortado (...)" (Frazer, 1944, p. 34). En ese sentido, para Frazer (1944) la magia de los primitivos carece de cualquier tipo de reflexión a propósito de sus procedimientos; estas sociedades se valen de ella, no para comprender, sino para hacer cosas, obtener ciertos efectos 
y transformar materialidades externas. Para el caso, en lo mágico se pone en juego una cuestión inherentemente práctica (Frazer, 1944).

Sobre esto último podría establecerse un primer puente, una primera tensión con un aspecto que menciona Foucault (1999a) a propósito de la palabra y no de la magia. Este autor menciona que hay un lenguaje del mundo, una palabra charlatana que se opondría a una palabra otra, una que se sostiene en el nexo oscuro entre el deseo y el saber, en la medida en que la primera posee un objetivo económico. En la palabra charlatana existe un vacío de sentido que pasa a ser saturado por el peso del juicio, aquel que tiene la capacidad de atacar o proteger aquello que designa; por ello

lo que carga este lenguaje no es lo que quiere decir, sino lo que quiere hacer. Sin decir nada está enteramente animado por sobreentendidos y remite a posiciones que le dan su sentido ya que por sí mismo no lo tiene. (Foucault, 1999a, p. 152)

Así, en la magia entendida por Frazer (1944) y en esta clasificación de la palabra que hace Foucault (1999a), prevalecen cuatro elementos que es necesario tener en cuenta para posteriormente desglosarlos, refutarlos o ponerlos en suspenso: 1. En las dos situaciones hay una distancia con el saber; 2. Se apela a una exterioridad y a una materialidad distinta a la de las palabras mismas; 3 . En ambos gestos (la magia y la palabra charlatana) está la posibilidad de beneficiar o perjudicar a eso Otro que se alude, o a lo que se dirige; 4 . Como se apela a una exterioridad, tanto la palabra charlatana como el acto mágico, funcionan como irrupción.

Ahora bien, decir que la práctica mágica no supone un razonamiento sobre sus procedimientos no significa que la magia no posea reglas de funcionamiento específicas que clasifiquen y determinen su operatividad. Frazer (1944) menciona que cuando se habla de magia simpatética ${ }^{1}$, existe una subdivisión de dos ramas: la homeopática y la contaminante. En ambos casos, según el autor, se parte de la idea según la cual existe una atracción secreta, una simpatía oculta entre las cosas que actúa como una fuerza, generando efectos so pena de la distancia y el tiempo, de manera recíproca (Frazer, 1944).

A propósito de esto cabe resaltar dos cosas: 1. Tal idea de que hay una fuerza que enlaza a las cosas, operando más allá del espacio y el tiempo, también pasará a ser fundamental en la episteme del siglo XVI,

Según lo da a entender Frazer (1944), pareciera que existiera otro tipo de magia, además de la simpatética, sin embargo, el autor no la menciona, no hace ninguna aclaración a propósito de ella o, dado el caso, de esa apenas insinuación que se hace de ésta. 
tal y como la entiende Michel Foucault y 2. Este tipo de comprensión no solo habla de la magia sino también del universo mismo; este funciona, según comenta el autor (Frazer, 1944) desde la asociación de ideas por semejanza y por contigüidad; es tal la manera en la que opera el pensamiento y, en consecuencia, es justamente aquello en donde radicaría, según el autor, lo que nos hace humanos.

Por otra parte, cada tipo de asociación se traduce en una afirmación que, a su vez, supone el principio de funcionamiento de cada una de las ramas de la magia: por un lado, lo semejante produce lo semejante (magia por contagio) y por el otro, lo que estuvo unido permanece unido (magia homeopática) (Frazer, 1944). Así entonces, y tal y como lo aclara el autor, cuando se habla de magia no se está hablando de un agente consciente que imita sino, por el contrario, de un sujeto que está en consonancia con una lógica universal de imitación que lo desborda y lo contiene.

La comprensión de lo anterior podrá ser beneficiosa o perjudicial en grado sumo, en la medida en que la asimilación de tal lógica de imitación afectará, principalmente, la muerte o la vida. De ahí los ejemplos que presenta el autor en los que se pone en juego ambos elementos, evidenciando con esto la potencia del acto mágico:

[Entre los indios ojebway] si se quiere matar al enemigo a toda costa, se atraviesa su imagen de los pies a la cabeza, se le amortaja como si fuera un cadáver, se reza sobre ella cual si estuviera rezando por un muerto y después se le entierra en medio del sendero por donde el enemigo ha de pasar. Con objeto de que su sangre no caiga sobre la propia cabeza, se debe decir: "Yo no soy el que está enterrándole. Es Gabriel² el que está enterrando". (Frazer, 1944, p. 37)

(...) Entre algunos de los dayakos de Borneo, cuando una mujer tiene un parto laborioso, llaman a un brujo, que intenta facilitar el parto por el modo racional de manipular en el cuerpo de la parturienta y, mientras tanto, otro brujo, por fuera del cuarto, se esfuerza en obtener el mismo fin por medios que nosotros consideramos totalmente irracionales. En efecto, él pretende ser la parturienta: con una tela enrollada al cuerpo, sujeta una piedra grande que representa al niño en la matriz y, siguiendo las instrucciones que le grita su colega desde el lugar de la escena real, mueve el supuesto bebé sobre su cuerpo imitando exactamente el movimiento del verdadero, hasta que éste nace. (Frazer, 1944, pp. 37-38)

A propósito de este nombre el autor aclarará: "la culpabilidad del crimen recaerá sobre los hombros del arcángel Gabriel, que está mucho más capacitado para soportar este peso" (Frazer, 1944, p. 37). 
Tal y como se puede evidenciar, hay una intervención de las dos ramas de la magia; solo por nombrar algunos: la oración al muerto y la piedra que imita al niño (magia por contagio) y la imagen del enemigo (magia homeopática). Asimismo, en ambos casos la palabra encuentra su lugar, ya sea a modo de rezo, de conjuro que espanta la culpabilidad o indicaciones que aseguran la efectividad del acto mágico. Sin embargo, este punto amerita unas consideraciones más amplias pues, ciertamente, el lugar que ocupan las palabras dentro del rito resulta significativo.

En el primer ejemplo, aquel que habla de cómo dar muerte al enemigo, es de resaltar el lugar de las palabras finales, a saber: "Yo no soy el que está enterrándole. Es Gabriel el que está enterrando". Tal negación, que a su vez es afirmación, implica un desplazamiento en el que la posición de quien habla, dentro del ritual, se dispersa y pasa a ser solapada por un Otro, en este caso, el arcángel Gabriel, quien pasa a funcionar como el directo responsable del acto a través del acto mismo de enunciación.

Lo anterior implica el reconocimiento de una tensión entre lo real y la verdad que se busca construir desde y al interior de la palabra que interviene en el acto mágico pues, en términos fácticos, la culpabilidad recaería en Otro que no es el ángel Gabriel, pero por efectos del hechizo y la irrupción y verdad que se construye en él, es Gabriel quien pasa a detentar dicha posición. Ahora, como el lector puede notar, esas palabras son, en sí mismas, la producción de una distancia en la que lo Uno se separa y se deja suplantar por lo Otro, velando su participación; sin embargo es allí, en ese espacio, en donde a su vez la semejanza adquiere otro pliegue, pues, tanto el ejecutor del acto mágico como la figura de Gabriel, conocido como el ángel mensajero ${ }^{3}$, se valen de la palabra y trazan con ella una distancia.

Es más, tal juego entre lo Uno y lo Otro, en tanto posiciones que se abren y solapan entre sí, resulta exacerbado al momento de hablar de otro de los usos de la magia homeopática: la curación y prevención de enfermedades. En ella ocurre, en palabras del autor, uno de los grandes méritos de este tipo de magia: "permitir que la curación sea ejecutada en la persona del doctor en vez de la de su cliente, quien se alivia de todo peligro y molestia mientras ve al médico retorcerse de dolor" (Frazer, 1944, p. 40).

Aunque en algunas situaciones el arcángel Gabriel (fuerza de dios) cumple funciones cercanas a las del arcángel Miguel, encargado de los ejércitos de dios, su particularidad radica en el manejo de la palabra, en tanto emisario del verbo divino. Mensajero encargado de la anunciación a la virgen, quien resulta inflamada por el verbo y el espíritu santo. 
Para el caso, es el cuerpo el que funciona como territorio de imitación; es en él donde ocurre el movimiento en el que cliente y brujo juegan a fundirse sin perder sus particularidades y su posición en el rito. Esto a tal grado que lo que ocurre en el cuerpo de uno, marcándolo, encuentra sus efectos en el del otro. Tal juego trae consigo una dinámica particular entre ausencia y presencia, lo cual lleva a la idea de que la magia tiene como condición de posibilidad el reconocimiento de una distancia y, en consecuencia, la aprehensión de una ausencia, su presencia lejana: el cuerpo del paciente, la enfermedad que no habita en el brujo, el enemigo que no está pero que es evocado, la vida y la muerte que no se poseen pero que están por venir, que se llaman, que se desean.

Es la ausencia la que le da lugar al acto mágico y a la palabra que allí interviene. A propósito de ello, resulta significativo mencionar que para Foucault (1999b), en la modernidad, ocurre un pliegue al interior del lenguaje, uno que no da nuevos contenidos sino nuevas posibilidades y que tiene como condición de posibilidad, la presencia de una ausencia, si se quiere, primordial: La muerte de Dios, aquella que mencionaba Nietzsche. Es ella la que, de acuerdo a Foucault, se constituye como el espacio de nuestra experiencia (1999b), aquella donde la palabra funciona como "la profanación que designa la ausencia y la conjura" (Foucault, 1999b, p. 164), no para restituirla en su presencia, sino para mostrarla en su lejanía.

Así las cosas, se identifica un tratamiento distinto de la ausencia, aunque en los dos funciona como epicentro de la acción. En el caso de Frazer pareciera subsistir esa dicotomía entre ausencia y presencia, mientras que en Foucault, el nombrar la ausencia trae consigo un modo de presencia, uno que, dado el caso, podría asemejarse a la apelación al arcángel Gabriel, esos momentos en donde la palabra se basta a sí misma, construye al interior de sí misma y no apunta a una exterioridad que la legitime.

Por otro lado, en el segundo ejemplo que ofrece el antropólogo, las palabras no parecieran ocupar un papel protagónico, sin embargo, es necesario aclarar que es solo gracias a ellas que se cataliza la emulación, aquella donde se zanja la separación entre el interior y el exterior, lo real de lo que resulta imitación. Así mismo, es allí donde se posibilita el encuentro de ambas superficies (interior/exterior o real/imitación). Esto último en la medida en que ambos pasan a operar en función de la vida, ejerciendo así como sus condiciones de posibilidad.

Ahora bien, la cuestión no se zanja allí del todo pues, según el autor, hay cierta racionalidad en esa primera imitación, aquella que ocurre en el interior y en donde un primer brujo manipula directamente el cuerpo de la 
mujer que va a dar a luz, comportándose como una partera. Ciertamente, la racionalidad que comenta el autor está basada en el contacto directo entre el brujo y la mujer, pero habría que cuestionar, teniendo claro que cada elemento del rito mágico hace parte de un todo orgánico, si lo propiamente mágico ocurre en el primer brujo o en el que está afuera.

De hecho, si nos atenemos a las conjeturas lanzadas anteriormente, el acto mágico ocurre es en la imitación que se lleva a cabo desde la exterioridad, pues es allí donde precisamente no hay contacto, la distancia se hace protagonista, la ausencia se hace presente y, en consecuencia, la repetición encuentra lugar.

Ahora, para cerrar las especificidades de Frazer en relación a la comprensión de la magia, cabe resaltar la importancia de los procedimientos y, en consecuencia, la rigurosa especificación sobre lo que debe y no debe hacerse. "Los preceptos positivos son los encantamientos; los preceptos negativos son los tabús" (Frazer, 1944, p. 43) y es a partir de ellos que se llama o coarta la acción, en pro de la obtención de determinados fines.

Expuestos los principales elementos de la magia, desde aquel que se ocupó directamente de entender los mecanismos que sustentan dicha práctica al interior de las sociedades primitivas, es importante fracturar la linealidad espacial que impone la escritura, estableciendo diálogos entre los autores, dando paso a una simultaneidad en donde las tensiones, distancias, abismos y zanjas se hacen visibles y protagonistas, pues hasta el momento solo se han dado un par de puntadas en esta dirección, aquella donde la visión se abre y da cuenta del espesor de la escritura, más que de su continuidad. De ahí que se decida recurrir y continuar con Foucault, autor con el cual, en principio, parecieran más evidentes las confluencias; es en él donde se condensa la lógica de nuestro tejido, así como los nudos básicos de su urdimbre.

Para el caso, una de las primeras cosas que llama la atención y que resulta significativa es la repetición de enunciados. Tal repetición, claro está, no excluye los desplazamientos, cambios o giros que hacen que, aunque se trate de la misma construcción verbal, ésta pase a funcionar en formaciones discursivas distintas y a propósito de objetos y objetivos diferentes.

Así, Foucault afirma, a propósito de la episteme del siglo XVI, que las palabras no estaban desligadas de cierto componente mágico, al fin y al cabo, se hablaba de signatura; el mundo como libro atestado de signos 
mágicos que dan paso a la divinatio (Foucault, 1968), entendida como la comprensión de ese juego de espejos en el que las semejanzas apelan unas a otras y, además, en donde se entiende que conocer es un acto inherentemente mágico.

En ese sentido, la semejanza se reafirma como parte constitutiva de la magia y se imbrica de tal modo que incluso pasa a establecer nexos con el conocimiento y sus procedimientos. Así también, es posible observar que para Frazer el principio imitativo funciona como eje rector del pensamiento o, en otras palabras, como una episteme, una rejilla o modo de comprensión desde el cual las posibilidades se organizan y dan paso a la acción en el universo y la naturaleza. Otra cosa es que la mirada del autor lo aborde desde una comprensión desligada del saber.

Lo anterior trae consigo un recorte pues, si bien para Frazer el principio de semejanza es indiferente al momento histórico, para Foucault este sí se encuentra absolutamente arraigado a las condiciones particulares, las fuerzas que confluyeron en dicha época y que dieron paso a pensar lo mágico desde la palabra y su relación con las cosas. Tal aspecto no resulta minúsculo si se tiene en cuenta que, en el caso de Frazer, no se está hablando de una condición del pensamiento humano sino de una determinación que permea la comprensión y la mirada que se puede llegar a establecer con la naturaleza y la totalidad del universo, en determinados grupos sociales. Un origen, una esencia unívoca y constante, uno que no nace de las palabras pero que las permea.

Hecha esta primera salvedad habremos de entregarnos a los embates foucaultianos, aquellos que primero andarán las sendas de las palabras y las cosas y que luego, de manera un tanto más minuciosa, se entregarán al encanto de los susurros presentes en la literatura. Ambos momentos suponen pistas, formas de existencia de la magia, cuyo espacio de realización no es otro que la palabra.

\section{De encantos y hechizos: espacio, semejanzas y espejos}

Para ahondar en la mirada foucaultiana y adentrarnos en los vericuetos de este tejido, es necesario digerir pacientemente lo que apenas ha sido un destello en este texto. Es importante puntualizar las reglas de funcionamiento que operaron durante el siglo XVI y que constituían una forma de saber, así como un modo de existencia del lenguaje y del mundo, de manera simultánea (Foucault, 1968). 
Así, mientras Frazer hablaba de una lógica de imitación, Foucault habla, para el siglo XVI, de la semejanza como elemento organizador, aquel desde el cual las cosas se hacían abordables, comprensibles y, sobre todo, leíbles. Para la época, se entendía que "el mundo se enrollaba sobre sí mismo" (Foucault, 1968, p. 26) en una especie de doblez cuyos movimientos, formas o maneras, se traducían en: conveniencia, emulación, analogía y simpatía.

En el caso de la conveniencia, nos referimos a la vecindad, a esa semejanza de las cosas que no pertenece a ellas mismas, sino que ocurre en el mundo, en el espacio en el que éstas se encuentran (Foucault, 1968). Sin embargo, esta exterioridad también funciona como "el signo de un parentesco oscuro" (Foucault, 1968, p. 27) que solo la semejanza hace visible, creando con ello un nexo entre las cosas, una cadena cuyos extremos son Dios y la materia: dos puntos que se encuentran y funden, evocando, con ese movimiento, una difusa diferenciación entre el adentro y el afuera de las cosas y de las palabras que son ellas mismas y su signo.

Ahora, la semejanza también se abre lugar en el espacio y entra a operar en la distancia, dando paso así a la emulación, aquella manera en la que hay algo "del reflejo y del espejo; por medio de ella se responden las cosas dispersas a través del mundo" (Foucault, 1968, p. 28), creando proximidades que dan lugar al enfrentamiento que no anula la distancia entre las cosas, sino que, en palabras del autor, la deja visible.

De hecho y en relación al enfrentamiento que se suscita a partir de esta forma de semejanza, Foucault (1968) dice: "Esta similitud se puede convertir también en el combate de una forma contra otra o mejor dicho, de una misma forma separada de sí por el peso de la materia o la distancia de los lugares" (p. 28). Es decir, se comporta como una división de lo Uno, una dispersión de la unidad que posibilita lo Otro, otro que, aunque distante en el orden del espacio, resulta ser el mismo.

Entonces, en este caso, la relación entre lo Uno y lo Otro no supone una suplantación como sí ocurría en la enunciación del arcángel Gabriel; aquí se trata de un encuentro, un choque que se traduce, si bien no en la anulación de la distancia, sí en la puesta en escena de la máscara: el Uno haciéndose pasar por Otro, evidenciando su dispersión o ese tipo de ubicuidad que se hace posible en el elemento del espejo. Dos que son dos, pero a la vez uno, uno que permanece en tensión aun desde la distancia. 
He aquí, en estas primeras dos maneras o formas de la semejanza, los mismos principios que mencionaba Frazer (1944) a propósito de la magia; la misma funcionalidad en dos discursos distintos, a propósito de contextos diferentes y con alcances particulares en cada caso pues, mientras para Frazer la magia constituye, ante todo, una serie de prácticas humanas que se ligan al principio de imitación propio de la naturaleza, para Foucault, la magia configura toda la episteme del siglo XVI, comportándose como un eje constitutivo que no es natural sino que responde a ciertas condiciones y particularidades que dan forma a la comprensión del mundo, el saber y el lenguaje de una época.

Por su parte, en la analogía se conjugan tanto la conveniencia como la emulación, comportándose de manera más sutil, menos evidente. Aquí tampoco se anula el enfrentamiento, pero sí se reconoce una posición privilegiada: el hombre; es él, "el gran foco de las proporciones -el centro en el que vienen a apoyarse las relaciones y de donde son reflejadas de nuevo" (Foucault, 1968, p. 32), no porque él las produzca, sino porque él mismo ha sido marcado por esos signos que, de manera ineludible, lo ligan a las plantas, los planetas, los animales, la naturaleza y todo lo que existe. Con ello se da espacio a una dinámica en la que microcosmos y macrocosmos se apelan entre sí, demarcan el límite de lo posible y ubican al hombre como intersticio:

Erguido entre las fases del mundo, tienen relación con el firmamento (su rostro es a su cuerpo lo que la faz del cielo al éter; su pulso palpita en sus venas como los astros circulan según sus vías propias; las siete aberturas forman en su rostro lo que son los siete planetas del cielo); pero equilibra todas estas relaciones y se las reencuentra, similares, en la analogía del animal humano con la tierra en que habita: su carne es gleba; sus huesos, rocas; sus venas, grandes ríos; su vejiga, el mar y sus siete miembros principales, los siete metales que se ocultan en el fondo de las minas. El cuerpo del hombre es siempre la mitad posible de un atlas universal. (Foucault, 1968, p. 31)

Por último, la simpatía juega en las profundidades (Foucault, 1968), surge de un único contacto y se establece sin caminos prefijados $\mathrm{y}$, en consecuencia, ejerce aproximaciones insospechadas que, nuevamente, conllevan movimientos en el interior de las cosas. De ahí que se diga que la simpatía transforma siguiendo el hilo de lo idéntico, de lo mismo (Foucault, 1968), ese hilo que, si no encuentra una ruptura en forma de antipatía, condensaría el todo en un mismo reflejo. El mundo devorándose a sí mismo. La multiplicidad hecha unidad. 
De ese modo y de acuerdo a las especificaciones de cada una de las formas de semejanza, es posible decir que esta no solo constituye un saber que procede por acumulación (Foucault, 1968), en la medida en que tanto la cadena de la conveniencia, como los reflejos de la emulación, el espacio de irradiación en la analogía y la pareja simpatía-antipatía, entrañan una red de signos en donde la comprensión de una cosa remite a la relación que esta guarda con otras y, en extenso, con todo lo demás, sino que, incluso desde sus formas, opera una especie de in crescendo que resulta en la condensación de las maneras: la simpatía.

Aclarado esto, es necesario hablar de la signatura, pues se entiende que "el mundo de lo similar solo puede ser un mundo marcado" (Foucault, 1968, p. 35) o, en otras palabras, un espacio atestado de signos, de escritura. Marcas que, tal y como se mencionaba en relación a la conveniencia, funden a la figura de Dios con la materia, haciendo que esta última sea, tal vez, su única posibilidad de presencia:

El rostro del mundo está cubierto de blasones, de caracteres, de cifras, de palabras oscuras -de "jeroglíficos" según decía Turner. Y el espacio de las semejanzas inmediatas se convierte en un gran libro abierto; está plagado de grafismos; todo a lo largo de la página se ven figuras extrañas que se entrecruzan y, a veces, se repiten. (Foucault, 1968, p. 35)

El universo es entonces, para el autor y su comprensión del siglo $\mathrm{XVI}$, un enorme y constante murmullo en donde las cosas traen consigo un juego de reflejos, de signos que deben ser leídos y que son duplicados por las palabras que los indican (Foucault, 1968). Lo anterior puede traer una serie de afirmaciones: 1. Las palabras son, fundamentalmente, duplicación, igual que los signos que componen el mundo; 2. Si las cosas son una red de reflejos, la comprensión del mundo del siglo XVI no establece una relación de exclusión entre imitación y realidad, cosa que, al mismo tiempo, hace de la semejanza una forma de saber. Para el caso, todo se refleja, incluso Dios y su escritura originaria solo es pensable desde su apariencia terrenal en las cosas (de nuevo, lo Uno y lo Otro); 3. La semejanza trae consigo la posibilidad de hablar, de que cualquier cosa pueda decir algo de sí y de la estructura que la sostiene (Foucault, 1968); 4. Del número anterior se desprende el hecho de que hablar es establecer relaciones y, en esa vía, repetir, traer una y otra vez el tejido, la red que posibilita la enunciación.

Es a partir de este juego de imágenes que apelan unas a otras que, por un lado, el saber de la época se torna una mezcla entre saber racional, nociones de prácticas mágicas y herencia cultural y que, por el otro lado, 
el lenguaje resulta ser una naturaleza fragmentada, un secreto con marcas descifrables, una revelación escondida y un signo de las cosas (Foucault, 1968). El lenguaje mismo como pliegue: un signo de signos que ocurre en el mundo y que se comporta, desde el autor, como una masa "opaca y misteriosa" (Foucault, 1968, p. 43).

Ciertamente, esto último viene dado desde la naturaleza misma de la signatura; ella es, al mismo tiempo, lo más visible y lo más oculto (Foucault, 1968). De ahí la imperiosa necesidad de la interpretación, esa lectura de lo oculto y de lo visible en la que los signos del mundo se duplican en los signos de las palabras y donde estas últimas catalizan otros más, otros que pasarían a integrarse a ese todo, al fin y al cabo, nada escapa a la semejanza, es ella su propio límite:

Se habla a partir de una escritura que forma parte del mundo; se habla al infinito de ella y cada uno de sus signos se convierte a su vez en escritura para nuevos discursos; pero cada discurso se dirige a esta escritura primigenia cuyo retorno promete y desplaza al mismo tiempo. (Foucault, 1968, p. 49)

En ese sentido, lo que el autor está presentando es el principio de proliferación intrínseco del lenguaje. Si Borges (Borges \& Ferrari, 2005) anunciaba que lo único que nos está dado es conjeturar, Foucault (1968) afirma que lo "lo único que hacemos es glosarnos" (p. 48) y tal vez, a fin de cuentas, siempre estemos hablando de un lenguaje por venir que, para el momento del siglo XVI, restituía una y otra vez la escritura divina (signatura), las marcas iniciales que hacían indiscernibles las palabras y las cosas y que, al finalizar el renacimiento, se traduce en el reconocimiento del espesor mismo del lenguaje, aquel cuyo espacio no es otro que la literatura (Foucault, 1968):

A partir del siglo XIX, la literatura vuelve a sacar a la luz el ser del lenguaje: pero no tal como aparecía a fines del renacimiento. Pues ahora ya no existe esta palabra primera, absolutamente inicial, que fundamentaba y limitaba el movimiento infinito del discurso: de aquí en adelante, el lenguaje va a crecer sin punto de partida, sin término y sin promesa. El texto de la literatura traza día a día el recorrido de este espacio vano y fundamental. (Foucault, 1968, p. 52)

Dicho esto, vale la pena recuperar las consideraciones más importantes: luego de desglosar la episteme del siglo XVI desde Foucault, cabe preguntarse si realmente aquello que presenta Frazer como una guía errónea de conducta que se fundamenta en la imitación y que era válida 
para la episteme de algunos grupos humanos (la magia), no constituye una forma de saber, como sí se especifica en los aportes foucaultianos, al hablar de la episteme occidental hasta el renacimiento. En esta última, saber y lenguaje funcionan desde una base mágica: la semejanza.

Es más, llama la atención el hecho de que dentro de la definición que ofrece el antropólogo se incluya la idea de ciencia falsa, un no-conocimiento que, desde la figura de apariencia que se abre desde el mismo momento en que se habla de imitación y semejanza, encontraría tensiones con la magia-saber del siglo XVI, expuesta por Foucault e incluso, ese no-saber que menciona Derrida (1968) a propósito de la escritura. Empero, todas estas conjeturas que se van hilando desde las palabras, se irán desarrollando a medida que estas mismas se desenvuelvan o plieguen entre sí.

Por otra parte, hay que tener en cuenta que si las cosas y las palabras se comportan como signos a interpretar, trayendo consigo toda una red de relaciones, no hay una distancia entre ambas o entre imitación y realidad; en esa vía, el mundo se comporta como un reflejo constante, uno que solo pasa a ser zanjado por la antipatía, en tanto principio de individualización que mantendría lo Uno y lo Otro en tensión persistente pues, ciertamente, aun desde la distancia, la semejanza (Foucault) continúa, acercándose con esa característica a la imitación (Frazer).

Entonces, tanto la semejanza como la imitación permanecen irreductibles, nada escapa a ellas, todo lo pensable y existente se encuentra inmerso en su red, pero, más importante aún, ambos principios suponen la base de aquello que podría llegarse a considerar como magia o, dado el caso, pensamiento mágico. Lo mágico ocurre en el momento en el que algo se comporta o presenta "como si" fuera otra cosa y, como ya se mencionó, tal movimiento solo es posible desde el reconocimiento de la distancia y ausencia que le da lugar en el lenguaje.

\section{Magia y ambigüedad: de curas y venenos}

Si se dice que la magia trae consigo el "como si", entendido como el desplazamiento entre lo Uno y lo Otro, es decir, entre la mismidad y la otredad que, en lo que aquí se expone, se dispersan entre sí, se afirma que las posiciones pueden tornarse ambiguas, así como los límites difusos. De hecho, en uno de los ejemplos de Frazer (1944) fue posible ver que el ángel Gabriel era el responsable del acto mágico pero que a la vez no lo era, pues sabemos que hay alguien que elabora la enunciación. En Foucault (2013), por su parte, se dio paso a la enunciación del Uno por el Otro, en tanto única posibilidad de presencia. 
Tales gestos, en conjunto, parecen aludir a cierto halo de simultaneidad irresoluta que resulta exacerbado en los postulados presentados por Derrida (1968) y su farmacia, esa que no es realmente de él sino de Platón, aunque solo gracias a Derrida (1968) nos enteramos que el texto de Fedro -diálogo que versa sobre la escritura-, constituye, básicamente, la presentación de una farmacia y, tal vez, el análisis de uno de los más potentes fármacos. De hecho, esto adquiere mayor profundidad (pliegues), si se tiene presente que incluso el texto de Platón es ya un doblez, uno en el que Platón y su escritura marcan palabras proferidas por otros, volviéndose así, para el caso, el único modo de presencia de esas ausencias que son, en esta ocasión, Sócrates y Fedro.

Nuevamente, quien lee estas líneas deberá disculpar lo laberíntico de la escritura, después de todo se enunció en el título de este apartado que las cosas podrían tornarse algo confusas; sin embargo, usted habrá de tener la certeza de que si lo confundo, es para que entienda, no desde la exterioridad de un lector bien sentado, sino desde la interioridad de estas palabras que quieren instigarlo a ver, a darle vueltas a lo mismo mientras le hablo de lo otro, desde aristas distintas, provocando que los pliegues se multipliquen.

En todo caso, lo que se intentará devanar en este apartado son las características del phármakon, tratando de eludir, en la medida de lo posible, las particularidades de la escritura, de las cuales se comentará más adelante. Así, bajo estas reglas de juego, resulta pertinente empezar por la afirmación de Derrida (1968): "si la lectura es la escritura, esa unidad no designa ni la confusión indiferenciada ni la identidad de toda quietud; el es que acopla la lectura a la escritura debe descoserlas" (p. 94) y, en consecuencia, los límites entre lo Uno y lo Otro, están marcados por una diferencia que los encuentra y que, a su vez, moviliza la categoría de identidad.

En esa vía, lectura-escritura es una unidad escindida, la presencia simultánea de lo Uno y lo Otro que se comporta como unidad y que, como los rostros de Jano ${ }^{4}$, son diferenciables, aunque indisociables. Ahora bien, con esto podría pensarse que todo cabe en medio de esas dos distancias que se encuentran juntas en el espacio, pero cuyas direcciones se dispersan y alejan entre sí; para aclarar ello, es necesario tener presente que tal ambigüedad no es el resultado de un error sino, por el contrario, 
de unas reglas de juego, unas reglas de funcionamiento que llevan a que el autor afirme que la escritura entraña un tejido oculto y que la lectura supone siempre adición (Derrida, 1968), añadiduras que se correspondan con esa textualidad y que a partir de allí coartan la arbitrariedad. Así como en un juego puede pasar todo lo que puede pasar ${ }^{5}$, sobre un texto podemos decir muchas cosas, pero no cualquier cosa o, si lo colocamos en palabras del autor: "Nada resulta aquí de una sola pieza y el Fedro juega también, en su escritura, a salvar - lo que es también perder- a la escritura como el mejor, el más noble juego" (Derrida, 1968, p. 97).

Por otra parte, el autor menciona que en el texto de Platón (Fedro), rápidamente se recurre, aunque con ironía, a la mitología; por ejemplo: el mito de las cigarras. A propósito de éste, Derrida (1968) rescatará el hecho de que, de acuerdo con Sócrates (el Sócrates ausente que vemos a partir de la presencia escrita de Platón y que vuelve a hacerse presente por Derrida, en esa lectura que decanta en escritura y que es adición): "La incompatibilidad de lo escrito y de lo verdadero se anuncia claramente en el momento en que Sócrates se pone a narrar cómo los hombres son puestos fuera de sí por el placer, se ausentan de sí mismos, se olvidan y mueren en la voluptuosidad del canto" (Derrida, 1968, pp. 99-100).

He ahí la presencia del deseo y el placer, pues Derrida (1968) especificará que es por un escrito que Sócrates accede a salir de la polis; la escritura como catalizadora del movimiento que arroja a la exterioridad, que hace salir de las vías naturales, aquellas que mantenían a Sócrates entre los límites de la ciudad y que solo por el deseo de acceder a lo escrito y a la belleza que podría ocultarse en él, se ven franqueadas.

En Derrida (1968), que es el caso de Platón y de Sócrates a la vez, el deseo arroja a la escritura que se dibuja como exterioridad o, dado el caso, el deseo es la escritura operando a distancia, atrayendo lo lejano, acercando lo distante y generando un desvío en el que lo natural se retuerce:

Sólo logoi en bibliois, palabras diferidas, reservadas, envueltas, enrolladas, haciéndose esperar en la especie y al abrigo de un objeto sólido, dejándose desear el tiempo de un camino, sólo letras así ocultadas pueden hacer comportarse de ese modo a Sócrates. (Derrida, 1968, p. 104)

\footnotetext{
Lo anterior supone un pequeño guiño a la teoría del juego de Huizinga, desde la cual se plantea que el juego es un territorio de amplias pero limitadas posibilidades, en donde incluso la trampa se tiene en cuenta. De ahí que, si corroboramos la analogía, en la lectura las añadiduras o retazos a tejer, pueden incluir la subversión del tejido original. Por otro lado, hay que tener en cuenta que el juego bien puede ser entendido como tejido de reglas, reglas que emergen de su propia práctica y que, en consecuencia, hablan de su propia capacidad para rehacerse y reacomodar sus límites.
} 
Ahora, es el mismo Sócrates diferido el que habrá de comparar el texto de Lisias con un fármacon pero, ¿qué implica esto y cómo se está entendiendo este término (phármakon)? En primera instancia se nos dirá que es esa "'medicina', ese filtro, a la vez remedio y veneno (...) Ese encantamiento, esa virtud de fascinación, ese poder de hechizamiento pueden ser - por turno o simultáneamente- benéficos y maléficos" (Derrida, 1968, p. 102).

De ahí que Derrida (1968) insista en el problema de la traducción de la palabra pues, por lo general, dicha ambivalencia pasa a ser obviada y cercenada por solo una de las faces que la componen, y no es presentada desde esa ambigüedad que le da forma y lugar dentro del discurso. Ahora, ya en Frazer (1944) se decía que la magia podía funcionar en estas dos vías, dando paso a la vida o a la muerte, beneficiando o perjudicando en grado sumo so pena de la distancia y el tiempo; incluso en Foucault (1999a), tuvo lugar esta ambivalencia en tanto riesgo de esa palabra charlatana que no se restringe a lo escrito y que juzga y se hace presente desde su vacío de sentido. He aquí la posibilidad de la palabra de entregarse a vías que resultan contrarias entre sí y que, por otra parte, la reafirman como exterioridad que irrumpe en el orden de las cosas: llevando a Sócrates al campo, fracturando la vida, dando paso a la muerte del enemigo y estableciendo un valor sobre las gentes y las cosas.

Dicho esto, y teniendo en cuenta el territorio movedizo en el que nos instala, detengámonos en la red de palabras que se tejen alrededor del fármacon y, en consecuencia, de la escritura. En la definición previamente presentada confluyen términos como medicina, filtro, remedio, veneno, encantamiento, fascinación, hechizamiento y la posibilidad abierta de la simultaneidad de contrarios (de lo Uno y lo Otro). Con esos términos, y si se quisiera hacer una clasificación de los mismos, podría hablarse de las condiciones de existencia (rasgos irreductibles, aunque móviles de acuerdo a las circunstancias) y de las reglas de funcionamiento (principios de operatividad que incluirían los efectos de su presencia o puesta en ejercicio) que dan forma al acontecimiento en el que el fármacon resulta un modo de existencia de esa relación palabra-magia que aquí se teje y desteje:

\begin{tabular}{ll}
\hline Condiciones de existencia & Reglas de Funcionamiento \\
\hline Medicina, filtro, remedio, veneno, encantamiento & Virtud de fascinación, poder de hechizamiento, \\
y presencia simultánea de lo Uno y lo Otro. & simultáneamente, benéfico y maléfico. \\
\hline
\end{tabular}

De acuerdo a esto, el fármacon es un encantamiento que funciona desde la fascinación y el poder de hechizamiento. Sobre esto habría que 
decir que el encantamiento es una elaboración mágica (RAE, 1732) que, como ya se vio, remite a la apariencia de lo natural y al artificio en tanto elaboración artística, una construcción. Por su parte, en el caso de fascinación y de hechizamiento, la ambigüedad vuelve a encontrar lugar, pues en ambos términos podría hablarse de veneno y remedio: "Fascinación: 1. Tr. Engaño o alucinación. 2. Tr. Atracción irresistible." (RAE, 2014); "Hechizamiento: de hechizar 1. Tr. Ejercer un maleficio sobre alguien por medio de prácticas mágicas. 2. Tr. Seducir o cautivar intensamente a alguien" (RAE, 2014).

En todo caso, en ambos términos está la posibilidad de ser benéfico o perjudicial en grado sumo y, con ello, la posibilidad de resaltar cómo el tejido y cada uno de los elementos que lo integran dan cuenta de la regla de funcionamiento que teje la urdimbre misma: la ambigüedad, entendida como imposibilidad de elección entre lo Uno y lo Otro que repercute en simultaneidad y en el reconocimiento de una potencia cuya dirección se encuentra disociada. Un elemento que escapa:

El fármacon sería una sustancia, con todo lo que esa palabra puede connotar, en realidad de materia de virtudes ocultas, de profundidad criptada que niega su ambivalencia al análisis, preparando ya el espacio de la alquimia, si no debiésemos llegar más adelante a reconocerla como la anti-sustancia misma: lo que resiste a todo filosofema, lo que excede indefinidamente como no-identidad, no-esencia, no-sustancia, y proporcionándole de esa manera la inagotable adversidad de su fondo y de su ausencia de fondo. (Derrida, 1968, p. 102)

De manera similar ocurre aquí con el sin fondo que se menciona al final de la cita; al escapar a toda aprehensión de solo una de las aristas, no es posible hablar de esencia, de identidad, de unidad unívoca o de cualquier idea que posea un halo de confianza en un origen. Al parecer, en medio de la repetición, las máscaras entre lo Uno y lo Otro, la creación de fantasmas, la irreductible transgresión de los límites y el hecho de que la ambigüedad se instale como regla de funcionamiento, hace que la magia se constituya en un acontecimiento que no posee fondo o, en otras palabras, sin origen (ursprung).

De hecho, vale la pena retomar esa palabra que se abría desde la muerte de dios, aquella donde el deseo y el saber se conjugan, así como el límite y la transgresión, sin ser excluyentes entre sí. Palabra en la que es precisamente esa simultaneidad de contrarios la que "pone en juego algo más que estos elementos; los sitúa en una incertidumbre, en unas 
certidumbres inmediatamente invertidas, donde el pensamiento se traba rápidamente al quererlas captar" (Foucault, 1999b, p. 167).

¿A qué apunto con esto? Al punto en común que se dibuja desde estos dos tipos de palabra que menciona Foucault, el funcionamiento de la magia desde Frazer y la ambigüedad propia del fármacon. En todos los casos, se trata de algo que escapa a la comprensión y que no es posible agotar desde un pensamiento dialéctico en el que las clasificaciones habituales nos obligan a instalarnos en diferenciaciones que no admiten cercanía o simultaneidad y en donde, por otra parte, se persiste en la quimera del origen.

Al respecto y con ánimo de enfatizar en la pérdida o renuncia del origen, Derrida (1968) afirma que "por la escritura o por el mito, se significan la ruptura genealógica y el alejamiento del origen." (p. 109), así que resulta significativo volver al mito y a figuras como Zot (Thot) y Hermes, ambas deidades como benefactoras de la palabra que, como el ángel Gabriel, funcionan como figuras mensajeras, es decir, como entidades poseedoras de palabras que hacen presente a Otro y que los hace parecer una especie de logógrafos: seres de la no-presencia y de la no-verdad (Derrida, 1968), una pura apariencia de lo ausente.

Sin embargo, antes podrían hacerse algunas acotaciones a propósito del mito platónico de Zamus (que también es Ammón), dios de los dioses, y Zeuz, el semidiós. Para el caso, se dirá que Zeuz presenta el fármacon de la escritura como una obra de arte, "un poder obrero, una virtud operadora ${ }^{6}$. Este artefacto es un arte" (Derrida, 1968, p. 111) que se ofrece a la apreciación del Rey y Padre. Sin embargo, su respuesta no es otra que la del desprecio, aquella en la que evidencia los efectos nocivos del artificio: atenta contra la memoria en tanto repetición de un no-saber (rememoración) (Derrida, 1968).

Así las cosas, quien lea esto debe tener presente que, si se habla de artificio, es por su condición de construcción artística y por ende artificial, es decir, distante a lo natural; hecho que entre otras cosas corrobora el veneno que ya Zamus denunciaba a propósito de la escritura/fármacon: es un no-saber. Por su puesto, esto último implica una contracara: la idea según la cual el logos responde al orden natural, a la fisis; es un zôon (Derrida, 1968); idea que hace que, entre otras cosas, resulte natural el desprecio por ese artificio que atenta contra la lógica del Rey/Padre/Naturaleza: 
El logos es un hijo, pues, y que se destruiría sin la presencia, sin la asistencia presente de su padre. De su padre que responde. Por él y de él. Sin su padre no es ya, justamente, más que una escritura. Es al menos lo que dice el que dice, es la tesis del padre. La especificidad de la escritura estaría relacionada, pues, con la ausencia del padre. (Derrida, 1968, p. 113)

De acuerdo a Derrida (1968), al Dios padre le basta hablar; su ignorancia sobre la escritura no lo debilita, sino que, por el contrario, reafirma $\mathrm{su}$ posición y su habla. Su logos o discurso resulta inexorablemente potente, precisamente por ser él su padre vivo, la posición que lo profiere y defiende. En otras palabras, el discurso oral requiere siempre de una presencia que lo asista, que lo ancle y lo llene de verdad.

En contraste, "el deseo de la escritura es indicado, designado, denunciado como el deseo del huérfano y la subversión parricida." (Derrida, 1968, p. 114). El texto escrito busca prescindir de la presencia, obvia el respaldo del padre e ignora su amparo, así como el deber y vida que provienen de este. La escritura/fármacon como un saber medio muerto (Derrida, 1968) que hace salir de las vías de lo natural y que, a partir de allí, opera desde el epicentro de una ausencia, en este caso, la del Dios-padre-origen.

Ahora bien, en medio de este deslizamiento de las posiciones, el lugar del padre no permanece incólume y privilegiado ante la ambigüedad propia del apartado; después de todo, "el padre es siempre el padre de un ser vivo/que habla. Dicho de otro modo, es a partir del logos como se anuncia y se da a pensar algo como la paternidad" (Derrida, 1968, p. 119) y, en esa vía, son las causalidades las que se rompen y es el logos en tanto hijo, la condición de posibilidad misma del padre, de pensar en algo como el lugar del padre; esto, sin lugar a dudas, abre un cuestionamiento sobre las condiciones de posibilidad en tanto necesidad de una ley, una regla que, al fin y al cabo, se recrea en la práctica misma del juego de la palabra.

En todo caso, volvamos a la figura de Zot y con ella a la de Hermes, a quien se le adjudica "la dislocación subversiva de la identidad en general, empezando por la del principado teológico" (Derrida, 1968, p. 127). Zot es hijo de Amón-Re, padre de todas las cosas y engendrador por el verbo, quien también posee un origen en tensión: para la mitología egipcia el mundo nació de un huevo, pero en tanto creador de todo él es el origen del huevo que a su vez lo contiene. "Se le designa ora como pájaro-sol nacido del huevo, ora como pájaro originario, portador del primer huevo" (Derrida, 1968, p. 129). De nuevo, la pérdida de las causalidades entra en escena y hace que la pregunta por el tipo de relación que 
tienen ambas entidades (Zot y Ammón), se haga relevante. Al respecto Derrida comenta:

[Zot] Lleva los signos del gran dios-sol. Le interpreta como portavoz suyo. E igual que su homólogo griego Hermes, del que, por otra parte, no habla nunca Platón, representa el papel del dios mensajero, del intermediario astuto, ingenioso y sutil que hurta y se oculta siempre. (Derrida, 1968, p. 130)

Así y en tanto portador de los signos, Zot es el dios del significante (Derrida, 1968), es decir, aquel que da forma a los significados que le son propios a Ammón/Amon-Re/ Horus/Zeuz/ Zamus. Hermes y Zot como dioses de la palabra en tanto entidad material del verbo, su único modo de presencia, una forma vacía que, a diferencia de la palabra charlatana, no cae con el peso del juicio pues, para el caso, este recae en la figura del Rey. En todo caso, esto implica que Dios padre y Dios hijo se encuentran en el acto creador: "representando Horus al pensamiento que concibe y Zot al habla que ejecuta" (Derrida, 1968, p. 130). Vuelve a aparecer así la dimensión práctica, pero con la particularidad que aquí no hay una disyunción entre el decir y el hacer como, al parecer, sí podría distinguirse en las descripciones de Frazer.

De acuerdo a esto, la posición secundaria de Zot/Hermes parece ineludible, sin embargo, si se recuerda, Derrida (1968) ya mencionaba que aquí nada es de una sola pieza y, en consecuencia, que aquí también sigue abierta la posibilidad del desplazamiento, ya sea en forma de metonimia o de subversión violenta (Derrida, 1968):

La escritura, como suplemento del habla. "Mientras que Re estaba en el cielo, dijo un día: Que venga Zot, y se lo llevaron. La majestad del dios dijo a Zot: Quédate en el cielo en lugar mío, mientras luzco para los bienaventurados en las regiones inferiores... Estás en lugar mío, me reemplazas, y te llamarán así: Zot, el sustituto de Re. Luego surgieron toda clase de cosas, gracias a juegos de palabras de Re. Dijo a Zot: Haré que abraces (ionh) a los dos cielos con tu belleza y tus rayos - y entonces nació la luna (ioh). Más adelante, aludiendo al hecho de que Zot ocupe, en tanto que sustituto de Ré, un rango algo subalterno: Haré que envíes (hób) mayores que tú. - entonces nació el Ibis (hib), el pájaro de Zot". (Derrida, 1968, p. 132)

Tal condición de suplemento no ocurre de manera tan simple, después de todo, su habla, aunque segunda, es también creadora y actúa en ausencia de Amón, en esa distancia que se abre entre ambos y que 
conforma un espacio de acción, un lugar para jugar a ser primero sin dejar de ser segundo; la posibilidad de un "como si" sumamente fecundo en el que lo Uno y lo Otro se solapan entre sí, en tanto posiciones. Tal funcionamiento puede evidenciarse en la anécdota de $\mathrm{Nut}^{7}$; Zot actuando en lugar de Re, para con ello abrir un tiempo que es espacio para la vida. La creación hecha parto.

Entonces, son muchos los atributos de Zot, aquel que conocemos también como Thot, dios egipcio de la medicina, la alquimia, la escritura, la luna, las ciencias ocultas, el tiempo, la magia, el cálculo, la aritmética, la astrología, pero también del juego de dados, el trictrac y el engaño como Hermes (Derrida, 1968); una deidad que incluso tiene injerencia en la muerte, una deidad-fármacon, una multiplicidad tan móvil y versátil como inaprehensible, aquella característica que permite el acto mismo de oposición/suplantación y que "pone en acción una lógica original: la figura de Zot se opone a su otro (padre, sol, vida, habla, origen u oriente, etc.), pero supliéndolo. Se añade y se opone repitiéndolo o teniendo su lugar" (Derrida, 1968, p. 137), en su propia otredad y potencia.

Así las cosas, Zot, en tanto comienzo de la escritura, es ante todo una distancia que repite y desplaza; Zot como una entidad que en su posición no-posición mensajera, se mueve y se desliza en y entre posiciones diversas, todas ajenas pero todas susceptibles de ser solapadas. Un intersticio. La exterioridad del fármacon irrumpe en el orden natural, es él la no-identidad como condición de existencia de Zot y, como se veía, del Fármacon (Derrida, 1968): Siempre "astuto, inaprehensible, enmascarado, conspirador, bromista, como Hermes, no es un rey ni un esclavo; una especie de comodín más bien, un significante disponible, una carta neutra, que da juego al juego" (Derrida, 1968, p. 138) y que, en consecuencia, es contenido y continente de este, su regla y su excepción.

Por ello, al ser una forma (¿o no-forma?) carente de significado estable, "su propiedad es la impropiedad, la indeterminación flotante que permite la sustitución y el juego" (Derrida, 1968, p. 138), los solapamientos, la impostura, ese juego de máscaras en el que Uno es reemplazado por el Otro, otro que puede ser cualquiera, por ejemplo, Zot: un vacío, un elemento sin fondo, sin rostro. De hecho, su ambivalencia interviene 
incluso en la muerte, allí donde se hace pasar por el muerto, allí donde la cura y el veneno se exacerban y se mecen en su balanza inexorable.

Una vez hecho este recorrido, solo queda la apariencia, el rastro de algo que fue, o que pareció ser, pero cuyos efectos no se ponen en duda. El fármacon como un elemento que, como un texto, opera por vía mágica, aquella que se mueve desde el deseo, lo oculto y el "como si" de las cosas. La magia como un movimiento inaprehensible que se socava y se repite, que mina su profundidad, que ocurre al interior del lenguaje y que juega en la distancia y la ausencia, aquellas que funcionan como sus condiciones de posibilidad y que, al mismo tiempo, conjuran la quimera del origen. Entre pliegues que se ocultan y muestran entre sí, creando espacios, ¿quién jugará a develar la palabra primera y última del juego que llamamos conocimiento?

\section{Referencias bibliográficas}

Borges, J. y Ferrari, O. (2005). En diálogo. México: Siglo XXI Editores.

Derrida, J. (1968). La farmacia de Platón. Recuperado de https://filologiaunlp.files.wordpress. com/2012/02/derrida-jacques-la-farmacia-de-platc3b3n-en-la-diseminacic3b3n. pdf

Foucault, M. (1968). Las palabras y las cosas. Buenos Aires: Siglo XXI Editores.

Foucault, M. (1999a). Un saber tan cruel. En Entre filosofía y literatura (pp. 149-162). España: Paidós.

Foucault, M. (1999b). Prefacio a la transgresión. En Entre filosofía y literatura (pp. 163-180). España: Paidós.

Foucault, M. (2013). La gran extranjera. Para pensar la literatura. Epublibre. Recuperado de http://ceiphistorica.com/wp-content/uploads/2016/04/Michel-Foucault-Lagran-Extranjera.pdf

Frazer, S.J. (1944). La rama dorada. Magia y religión. México: Fondo de Cultura Económica.

RAE. (1732). Diccionario Académico de Autoridades. En Nuevo Tesoro lexicográfico de la lengua española. Recuperado de http://buscon.rae.es/ntlle/SrvltGUIMenuNtlle? cmd $=$ Lema\&sec $=1 \cdot 0 \cdot 0.0 .0$

RAE. (2014). Diccionario de la lengua española (23a ed.). Recuperado de http://dle.rae. es/?id=P7dyaFK

Ruiz, F. (2017). Jano: el dios de dos caras. Vavel. Recuperado de https://www.vavel.com/es/ historia/2017/10/20/839164-jano-el-dios-de-las-dos-caras.html 